\title{
Urban geochemistry of lead in gardens, playgrounds and schoolyards of Lisbon, Portugal: Assessing exposure and risk to human health
}

\author{
A.P. Reis ${ }^{\mathrm{a}, *}$, C. Patinha ${ }^{\mathrm{a}}$, J. Wragg ${ }^{\mathrm{b}}$, A.C. Dias ${ }^{\mathrm{a}}$, M. Cave ${ }^{\mathrm{b}}$, A.J. Sousa ${ }^{\mathrm{c}}$, M.J. Batista ${ }^{\mathrm{d}}$, C. Prazeres ${ }^{\mathrm{d}}$, \\ C. Costa ${ }^{a}$, E. Ferreira da Silva ${ }^{a}$, F. Rocha ${ }^{a}$ \\ ${ }^{a}$ GEOBIOTEC, University of Aveiro, Campus de Santiago, 3810-193 Aveiro, Portugal \\ b British Geological Survey, Keyworth, Nottingham, NG12 5GG, UK \\ ' CERENA, Technical Superior Institute, Av. Rovisco Pais, 1049-001 Lisbon, Portugal \\ d LNEG, Estrada da Portela, Zambujal, 2720-866 Amadora, Portugal
}

\section{A R T I C L E I N F O}

\section{Article history:}

Available online $\mathrm{xxxx}$

\begin{abstract}
A B S T R A C T
To assess the impact of potentially harmful elements in soil/dust on the health of children that use urban recreational areas to play outdoors, an urban survey of Lisbon, the largest city in Portugal was carried out, collecting soils and dusts from public gardens, parks, playgrounds and schoolyards. An exposure and risk assessment study for the incidental soil/dust ingestion of lead was carried out based on US EPA guidelines using a sub-set of 19 topsoil and 8 outdoor dusts, out of a total of 51 samples, incorporating oral bioaccessibility measurements using the Unified BARGE Method developed by the Bioaccessibility Research Group of Europe. The objectives are: (i) interpretation of soil and dust oral bioaccessibility measurements; (ii) assessment of site-specific exposure and non-carcinogenic risk posed by lead; (iii) hazard assessment for urban soil and dust with respect to children playing in outdoor recreational areas. The results show that significant fractions of $\mathrm{Pb}$ occur in bioaccessible forms, $24-100 \%$ in soils and $35-$ $100 \%$ in dusts and the associated risk is greater for dust ingestion than for soil ingestion in Lisbon city recreational areas.
\end{abstract}

(ㄷ) 2013 Elsevier Ltd. All rights reserved.

\section{Introduction}

Due to their physiological and behavioural characteristics, children are exposed to some environmental contaminants to a greater extent than adults. Toxic chemicals in the environment can cause neurodevelopmental disabilities, and the developing brain can be particularly sensitive to environmental contaminants (US EPA, 2009). For example, elevated blood lead $(\mathrm{Pb})$ levels and prenatal exposures to relatively low levels of $\mathrm{Pb}$ (e.g. geometric mean value of $80 \mathrm{mg} \mathrm{kg}^{-1}$ (Johnson and Bretsch, 2002)) in soil can result in behavioural disorders and reductions of intellectual function in children (Lanphear et al., 2005; Landrigan et al., 2005).

Over the last decade a number of studies have investigated the exposure of children to urban particulate materials since the exposure of children to potentially harmful elements (PHE) in recreational areas is particularly high (during games at school breaks and in public playgrounds after school), with some researchers concentrating their efforts on the chemical and mineralogical composition of playground soil and dust (Ottesen et al., 2008; Okorie et al., 2011; Costa et al., 2012). The ingestion of soil and dust is an important exposure pathway to environmental chemicals and

\footnotetext{
* Corresponding author. Tel.: +351 234370804; fax: +351 234370605.

E-mail address: pmarinho@ua.pt (A.P. Reis).
}

children, in particular, may ingest soil and dust through deliberate hand-to-mouth movements, or unintentionally by eating food that has dropped on the floor (US EPA, 2011; Bacigalupo and Hale, 2012). For example, soil ingestion is referred to in a number of case studies as a probable source of $\mathrm{Pb}$ exposure in children with elevated blood $\mathrm{Pb}$ levels in some areas (Johnson and Bretsch, 2002; Laidlaw and Filippelli, 2008; Morrison et al., 2012). High concentrations of $\mathrm{Pb}$ in urban soils and dusts have become a potential source of risk to children because $\mathrm{Pb}$ has become widely dispersed in the urban environment (Charlesworth et al., 2003; Li and Huang, 2007; Morton-Bermea et al., 2008; Laidlaw and Taylor, 2011).

Understanding soil and dust ingestion patterns is an important part of estimating overall exposures to PHE. As such, investigations of soil and dust ingestion rates among young children have led to numerous studies and recommendations with respect to point-estimate values for soil and dust ingestion (Moya et al., 2004; US EPA, 2009; Okorie et al., 2012). The Child-Specific Exposure Factors Handbook (US EPA, 2009) recommends an ingestion rate among young children (2-11 years) of $50 \mathrm{mg} \mathrm{day}^{-1}$ for soil and outdoor dust. Usually, the toxicity of an ingested PHE depends, in part, on the degree to which it is absorbed from the gastrointestinal (GI) tract into the body, i.e. on its oral bioavailability. In this study the term bioavailability refers to the relative bioavailability (US EPA, 2007). Different degrees of absorption result from the fact that a PHE in the 